\title{
25 Research Suare \\ Effects of Job Demands, Job Resources, and Workaholism on Overwork: A Cross-Sectional Survey in China
}

\section{XIN WANG ( $\square$ w_x_9887@hotmail.com )}

Capital University of Economics and Business https://orcid.org/0000-0002-5457-7011

Jing YANG

Beijing International Studies University

\section{Yoritoshi NAGAl}

Ehime University

\section{Research article}

Keywords: karoshi, overwork, fatigue, job demands, job resources, workaholism, employees, ocuupational health

Posted Date: April 8th, 2020

DOI: https://doi.org/10.21203/rs.3.rs-19946/v1

License: (c) (i) This work is licensed under a Creative Commons Attribution 4.0 International License. Read Full License 


\section{Abstract}

Background Overwork has become the common for some employees in China. The 'Healthy China 2030' plan mandates prevention of excessive overtime, making serious overwork was not advocated. Meeting new regulations requires clarification of the factors influencing overwork; however, Chinese researchers have not thoroughly examined 'overwork' and few proven models are available for addressing its relationship to job demands, job resources, and workaholism.

Methods This study analysed these factors and overwork among employees in Chinese companies. A total of 1047 employees completed the Workers Fatigue Accumulated Degree by Self-Diagnostic Questionnaire (WFAD-SQ) for Assessment of Workers' Accumulated Fatigue to measure the degree of overwork; Workaholism Battery (WorkBAT) was applied to evaluate workaholism; the Job content qualifications (JCQ) were adopted to survey job demands-resources.

Results Structural equation modelling (SEM) verified the effects shown, indicating job resources significantly negatively affect and job demands positively affect overwork. Workaholism demonstrated a significant intermediary role between job demands-resources and overwork. The SEM results indicate job demands-resources have both direct and indirect effects on overwork, and task demands, psychological requirements, and colleague support are the primary positive protective predictors for overwork.

Conclusions The findings indicate the importance of employers strictly enforcing overtime rules, ensuring staffs' rights for rest, and establishing harmonious working relationships between employees.

\section{Background}

In the early 18th Century, work time and the phenomenon of overwork demands were widespread in European countries; the term 'overwork' first appeared in Marx's book of 'Economic and Philosophical manuscripts' in 1844 [1]. In that period, the estimated annual working hours for a labourer in the United Kingdom or the United States was 3500 hours [2]. In the 20th century, around the 1950s, the overworking started to become common in Japan. In the 1960s, the time Japanese employees spent working, including overtime, reached its peak, with the average actual time spent working being 2400-2500 hours per year, although the legal limit was close to 2200 hours [3]. In 1969, the first professed 'sudden death' was recorded by the Health Ministry in Japan, after which the phenomenon became known as 'karoshi' (death from overwork) [2]. In October 1987, Japan's Health Ministry identified 'karoshi' as a labour disaster. With the continuous development of China's social and economic level, the problem of overwork has become increasingly prominent. Long term serious overwork will not only greatly impact people's physical and mental health but also lead to 'karoshi', 'depression due to overwork and suicide due to overwork in extreme cases [4].

In recent years, the problem of overwork has increasingly attracted the attention of society and academia. Compared with the research in the field of 'overwork' in other developed countries, China started late in this field, and only after 2000 did some scholars begin to pay attention to and engage in the research, and 
there are totally different characteristics in the distribution and evolution path of disciplines in this field in China: more emphasis on economics and law, but few research achievements in supporting disciplines such as medicine and psychology [5]. Therefore, reviewing the reasons for the formation of the practice of overwork and analyzing the factors related to this phenomenon may be conducive to producing a more profound analysis. The knowledge derived can also be applied to preventing overwork for employees and providing targeted countermeasures and recommendations. It's important to know the influence factors of overwork, however, very few studies can construct a model and be proved.

Uehata (1993) clearly defined 'Karoshi' from a medical perspective [6] and Fukuchi (2008) pointed out that overwork is a broken state of the 'physiological system that maintains balance in the human body' to the extent that the body cannot recover simply from 'several nights' sleep and a few days of rest, due to the balance of the nervous system' in which such disorders lead to a difficulty in maintaining a steadystate. Fukuchi further explained that such stress on these physiological systems cannot be maintained without causing irreversible physiological changes [7]. Senda (2003) argued that overwork is mainly due to the heavy labour burden caused by overly dense and long work hours [8]. Wang (2011) defined overwork as a labourer experiencing fatigue-of body or spirit-over a prolonged period to the point that their physical health/quality of work and the life of the labourer are impacted, pointing to the culture normalizing overtime and super labour as creating the problem due to the driving of various related factors [9]. Meng (2014) described overwork as the state that of a labourer adopting overtime and overly intensive work behaviours as their normal work process, which leads to fatigue accumulation that cannot be remedied after a small amount of rest [10]. Wang and Yang (2016) similarly described overwork as including both a 'behaviour state' and a 'result state', where the behaviour state is the state of working overtime and engaging in super work habits, and the 'results state' refers to the process by which the homeostasis of physiological function and the self-regulation mechanism and psychology of an individual are disturbed, and their health is in a state of imbalance which cannot be restored by short-term sleep and rest adjustment caused by workers' long-term work engagement-work amount, working time, work intensity, etc.-beyond their physical and mental capacities, creating fatigue that constantly accumulates [11].

Overwork is influenced by individual characteristics such as a person's physical and mental health levels, diligence, and the ease with which they adopt the corporate culture, as well as their attitude towards overtime, sense of responsibility, achievement motivation, degree of self-realization, et cetera [12-15]. Overwork is also affected by the organizational environment and culture of long work hours, excessive workloads, competitive workplace relations, unreasonable work-time management, and their wage system, incentive system, etc [16-19]. It is also impacted by globalization, the ICT revolution, 24-hour management, loose labour laws, labour contracts, government training, and other macro-environmental factors [20-21]. Additionally, differences in overwork have been noted relating to gender, marital status, and having a family [22-23].

Many scholars have shown that the higher the work requirements and the richer the work resources, the more engaged employees are in the work [24-26]. Additionally, it has been shown that higher job 
demands with fewer job resources result in a greater impact on employees' health [27]. High job demands create strain and often force workers to deal with a high volume of work to be done at a fast pace, and are consequently assumed to impair employee health [28]. Accordingly, the highest risk of ill-health is to be expected among those experiencing high job demands, low job control, and low social support at work [29]. However, there is little research on the relationship of job demands-resources to overwork, and how demands and resources lead to overwork has not been verified.

According to the 'heavy work investment perspective', 'workaholism' and 'work engagement' are two faces of the same coin [30].In the current study, workaholism and work engagement are considered together and crossed conceptually in order to identify different kinds of workaholics [31-32]. In light of the Job Demands-Resources (JD-R) model, there is a growing consensus on the influence of work environment characteristics on engagement [33-34]. Accumulating empirical research has shown that work engagement is negatively related to health problems [35]. However, work engagement may also absorb the individual in their work, thereby leading to long working hours and, thus, reducing time available for physical activity, which contributes to more overwork [36]. However, the relationship between workaholism and overwork has rarely been studied.

To examine this relationship, the following hypotheses were tested: $(\mathrm{H} 1)$ a direct and positive relationship between job demands and overwork exists; (H2): a direct and negative relationship between job resources and overwork exists; and, (H3) workaholism mediates the relationship between job demands-resources and overwork.

\section{Methods}

\section{Procedures and Participants}

The cross-sectional study was conducted in an area in China. Data collection and access were approved and supported by the China Moderate Labour Research Centre (part of the Human Resources Development Research Association of China) and the Capital University of Economics and Business Project team. Every year the China Moderate Labour Research Centre organizes an investigation of research about overwork, this being the fourth year. The research centre agreed to allow us to use the data and approved publication of the research. We released the questionnaire and invited participation by members of the research centre. Prior to the investigation, we informed participants that the questionnaire was limited to scientific research and that we would not reveal any personal information. Additionally, the beginning of the questionnaire included a statement clarifying that the survey was anonymous. The investigation ran from March to May 2015 and participants were from an area in China including 19 provinces, four municipalities directly under the central government, and two autonomous regions participated in the survey. Only the regions of Guizhou, Gansu, Ningxia, Xinjiang, and Tibet were not among those (not including Hong Kong, Macau, and Taiwan) participating in our sample of 512 companies. The study object was the group of all enterprise employees, 1350 of whom were invited to participate in the research, with a total of $1047(82.8 \%)$ of them completing all of the study questions. 
Covering 19 primary industry, such as manufacturing $(n=187,17.9 \%)$, finance $(n=80,7.6 \%)$, information services $(n=192,18.3 \%)$, wholesale and retail $(n=61,5.8 \%)$ and so on. Including state-owned enterprise staffs ( $n=461,44.0 \%)$, foreign investment enterprise staffs $(n=104,9.9 \%)$, joint ventures enterprise staffs $(n=52,5.0 \%)$, private enterprise staffs $(n=344,32.9 \%)$, and other forms of enterprise staffs $(n=81$, $8.2 \%)$. From the point of post type, including function duty $(n=293,28.0 \%)$, technical post $(n=212$, $20.2 \%)$, management duty $(n=329,31.4 \%)$, sales duty $(n=111,10.6 \%)$, and others $(n=102,7.7 \%)$. All study subjects were fully informed of the purpose of the study prior to their enrolment.

\section{Measures}

The Ministry of Health, Labour and Welfare of Japan's 'Workers Fatigue Accumulated Degree by Selfdiagnostic Questionnaire' was used to assess the degree and condition of overwork ${ }^{3}$ [37]; the Workaholism Battery (WorkBAT) was applied for workaholism [38]; the Job content Qualifications (JCQ) recommendations were used to measure leadership support, colleague support, facilities conditions, work control, mission requirements, skill requirements, and so on [39-40]. A structured questionnaire was administered to collect information on demographic characteristics (including gender, age, education level, marital status, personal income, living expenses) of participants. Age was categorized into three levels:

25 years old, $25-34$ years old, and

35 years old. Education level was categorized into 'associate's degree or below', 'bachelor's degree' and 'bachelor's degree above'; marital status was divided into single, married and others (included divorced and widowed); personal income was categorized into three levels:

4000 (yuan)/month, 4000-8000(yuan)/ month, > 8000 (yuan)/ month; and personal expense was categorized into three levels:

(yuan)/month, 2001-4000(yuan)/ month, > 4000 (yuan)/ month.

\section{Overwork}

Workers Fatigue Accumulated Degree by Self-Diagnostic Questionnaire (WFAD-SQ), the self-test diagnostic scale of fatigue accumulation was developed by the Ministry of Health, Labour, and Welfare of Japan (2003) [37] and has been validated in a range of healthcare settings in Japan, China, and some other countries [41-43]. The degree of overwork was measured by this scale, which is a kind of simple self-test questionnaire, mainly based on the developed medical research achievements. In the field of overwork research, this measure has been the most widely used in China. Scholars have conducted empirical testing with good results [44; 45-46]. This measure comprises 20 items, and is divided into two dimensions: sense fatigue (SF), 13 items, e.g., 'There is no motivation', 'Can't concentrate', $0=$ little, $1=$ sometimes, 3 = often), and workload (WL, 7 items, e.g., 'Overtime within one month', $0=$ appropriate, $1=$ much, 3 = very much; 'body burden during the work', $0=$ light, $1=$ heavy, $3=$ very heavy). Calculating scores of the two dimensions respectively (SF, four levels, I = 0-4, II = 5-10, III = 11-20, IV = 21 and above; WL, also four levels, $A=0, B=1-2, C=3-5, D=6$ and above), and dividing interval for total score (0-7). Scores ranging 0 to 1 indicate there is no likelihood of accumulated fatigue and the degree of overwork is 
null; scores ranging 2 to 3 indicate a small likelihood of accumulated fatigue and the degree of overwork is light; scores ranging from 4 to 5 indicate there is a high likelihood of accumulated fatigue and the degree of overwork is heavy; scores ranging from 6 to 7 indicate a very high likelihood of accumulated fatigue and the degree of overwork is very heavy. These classification standards have also been utilized by other Chinese scholars [47;10;45]. The Cronbach's alpha of the WFAD-SQ in the present study was 0.902 .

\section{Workaholism}

The WorkBAT was used to measure the degree of workaholism. Two additional scales are commonly used in this field: the WART and the DUWAS. The latter two are revised versions of the WorkBAT [48]. The WorkBAT comprises 25 items originally distributed along three subscales: work involvement (WI), consisiting of eight items, such as 'When I have free time I like to relax and do nothing serious'); drive (D) consisting of seven items, such as 'I seem to have an inner compulsion to work hard'; and, work enjoyment (WE) consisting of 10 items, such as 'My job is so interesting that it often doesn't seem like work' [38]. Each item is rated on a five-point Likert scale ranging from 5 (strongly agree) to 1 (strongly disagree). Scholars tend to link general job involvement with health and higher life satisfaction, but workaholism involves a degree of investment that has ill effects on health, and compared with healthy work engagement, it is linked to a higher risk of chronic diseases and overall dissatisfaction with life [4952]. The Cronbach's alpha of the WorkBAT in the present study was 0.854 .

\section{Job Demands-Resources}

Krasek (1979) presented the JD-C Model, which is one of the mainstream models for explaining the pressure sources from working [53]. Bakker etc. $(2004,2007)$ on the basis of JD-C Model, put forward the job demands-resource model (JD-R Model) [39-40]. JCQ was established on the basis of Karasek's job demands-resources control model, which have been translated into many languages [54-55]. A Chinese version of JCQ contains 36 items, including two dimensions of job demands: task demands (TD), e.g., 'My job requires me to work hard', and skills demands (SD), e.g., 'My job requires that I master a lot of professional technology proficiency, skills, and knowledge'). The JCQ also includes the dimensions of supervising work (SW), e.g., 'My boss often to supervise or check my work schedule and quality', and psychological requirements (PR), referring to the mental activity expended at work for thinking, decisionmaking, computing, and so on, and job resources. Job resources consists of leadership support (LS), such as, 'When I am experiencing trouble at work, my boss can give me help', colleague support (CS), such as, 'When I meet problem at work, my colleagues will give me a hand', facilities conditions (FC), such as, 'My company provides a good environment and working conditions', work control (WC), such as, 'My job allows me independent to decide a lot of things', organizational justice $(0 \mathrm{~J})$, such as, 'If my performance is outstanding, the company will give me to the opportunity of promotion and rewards'. The JCQ has been widely used in China and has been confirmed as having good reliability and validity [5658]. Each item is rated on a five-point Likert scale ranging from 5 (strongly agree) to 1 (strongly disagree). More help provided to employees from leaders and colleagues, along with better facilities, job autonomy space, and fair treatment in the organization, the more resources are given to the staff; the more mission 
requirements, skills needs, rigorous supervision at work, mental load, the higher the demands for the staff. The Cronbach's alpha of the JCQ in the present study was 0.905 .

\section{Statistical Analyses}

Epidata3.0 was used to input data, and SPSS20.0 for Windows and AMOS 20.0 were used for the statistical analyses. Used descriptive analysis for demonstrate demographic information and used variance analysis to evaluate the means, standard deviations and significance between observed variables and dependent variable. Pearson's correlation analysis was used to examine the simple relationships among job demands, job demands, workaholism, and overwork. Multiple linear regression analysis was applied to determine predictors for overwork while adjusting for demographic variables. Categorical variables were considered dummy variables. Model fitting was accomplished using a stepwise method with criteria for entry at

and removal at

to select potential predictors for the overwork and its two dimensions.

The structural equation model (SEM) was constructed using AMOS 20.0 to test the effects of job demands, job resources, and workaholism on overwork using the maximum likelihood method. Standardized path coefficients, as well as the significance of the direct, indirect and total effects were presented. The model will be estimated and inspected.

\section{Results}

In this research, the enterprise employees who did not indicate the phenomenon of overwork accounted for $24.7 \%(n=259)$. Three-quarters of all others were in a state of overwork, with $30.4 \%(n=318)$ of all enterprise staff belonging to the mild degree of overwork, $29.1 \%(n=305)$ the severe degree, and $15.8 \%$ $(n=165)$ in a heavy state of overwork.

The demographic information and the mean scores of the totals, SF, and WL are shown in Table 1. The average male overwork score was 3.79, indicating a more serious problem than the female score (3.18). Two independent samples T-tests, T-value $=4.37$, between male enterprise staffs and female enterprise staffs indicated a significant difference $(p<0.001)$. Of all employees, $61 \%$ of those had an associate's degree or below indicated a mild degree (or less) of overwork, but $46 \%$ of enterprise employees who have a bachelor's degree or above indicated a severe (heavy) degree of overwork. The $\mathrm{K}-\mathrm{W}$ test showed that a significant difference $(p<0.005)$ such that the higher educated, the more likely to be overworked; bachelor's degree was the watershed; however, SF scores did not show a significant difference between education levels. Total scores and WL scores were significantly higher in those with the personal income of more than 8000 yuan/month, and personal expenses of more than 4000 yuan/month.

Table 1. Mean scores for the overwork and its subscales $(n=1047)$ 
Demographic characteristics $\quad \mathrm{N}(\%) \quad$ overwork

\begin{tabular}{|c|c|c|c|c|}
\hline & & \multirow[b]{2}{*}{ Total } & \multirow[b]{2}{*}{ SF } & \multirow[b]{2}{*}{ WL } \\
\hline & & & & \\
\hline \multicolumn{5}{|l|}{ Gender } \\
\hline Male & $404(38.6)$ & $3.79(2.25)^{\star \star}$ & $3.72(0.45)$ & $2.54(1.02)^{\star \star}$ \\
\hline Female & $643(61.4)$ & $3.18(2.17)$ & $3.68(0.47)$ & $2.25(1.00)$ \\
\hline \multicolumn{5}{|l|}{ Age group } \\
\hline$<25$ & $138(13.2)$ & $3.17(2.24)$ & $3.72(0.49)$ & $2.22(1.07)$ \\
\hline $25-34$ & $679(64.8)$ & $3.40(2.19)$ & $3.69(0.46)$ & $2.35(1.01)$ \\
\hline$\geq 35$ & $230(22.0)$ & $3.60(2.29)$ & $3.69(0.46)$ & $2.46(1.03)$ \\
\hline \multicolumn{5}{|l|}{ Education level } \\
\hline Associate's degree or below & $335(32.0)$ & $3.19(2.21)$ & $3.73(0.44)$ & $2.23(1.04)$ \\
\hline Bachelor's degree & $534(51.0)$ & $3.53(2.23)$ & $3.68(0.47)$ & $2.43(1.01)$ \\
\hline Bachelor's degree above & $178(17.0)$ & $3.50(2.21)$ & $3.69(0.46)$ & $2.40(1.01)$ \\
\hline \multicolumn{5}{|l|}{ Marital status } \\
\hline Single & $460(43.9)$ & $3.37(2.21)$ & $3.72(0.45)$ & $2.32(1.04)$ \\
\hline Married & $582(55.6)$ & $3.45(2.23)$ & $3.68(0.47)$ & $2.38(1.01)$ \\
\hline Divorced/ Widowed & $5(0.5)$ & $3.80(2.17)$ & $3.60(0.55)$ & $2.60(0.89)$ \\
\hline \multicolumn{5}{|l|}{ Personal income } \\
\hline$<4000$ yuan/month & $266(26.1)$ & $3.29(2.30)$ & $3.71(0.45)$ & $2.29(1.06)$ \\
\hline $4000-8000$ & $522(51.2)$ & $3.31(2.17)$ & $3.66(0.47)$ & $2.32(1.00)$ \\
\hline
\end{tabular}

Total: degree of overwork; SF: sense fatigue; WL: work load.

Values are means and standard deviations (in parentheses).

${ }^{\star} p<0.05,{ }^{\star \star} p<0.01$ when compared with the last group.

The correlation coefficients between the study variables and overwork are shown in Table 2 . The scores for the two sub-scales of workaholism and four sub-scales of job demands related positively with labour, $S F$, and WL, whereas the scores for the five sub-scales of job resources correlated negatively with them. Work investment and drive as sub-scales of workaholism have a positive relationship with overwork, job demands, and job resources and their sub-scales, whereas work enjoyment presented as having a negative relationship to overwork and job demands and their sub-scales. 
Table 2. Correlation between overwork, workaholism and others

\begin{tabular}{|c|c|c|c|c|c|c|}
\hline & overwork & SF & WL & WI & D & WE \\
\hline overwork (OW) & & $0.300^{* *}$ & $1.000^{\star *}$ & $0.307^{\star \star}$ & $0.085^{* *}$ & $-0.064^{*}$ \\
\hline sense fatigue (SF) & $0.300^{* *}$ & & $0.301^{\star *}$ & $0.187^{\star \star}$ & $0.062^{\star *}$ & $-0.127^{*}$ \\
\hline work load (WL) & $1.000^{\star \star}$ & $0.301^{\star \star}$ & & $0.305^{\star \star}$ & $0.086^{\star *}$ & $-0.063^{*}$ \\
\hline \multicolumn{7}{|l|}{ workaholism (WA) } \\
\hline work involvement (WI) & $0.307^{\star \star}$ & $0.187^{\star \star}$ & $0.305^{\star \star}$ & & $0.433^{\star *}$ & $0.326^{* \star}$ \\
\hline drive (D) & $0.085^{* *}$ & $0.062^{*}$ & $0.086^{\star \star}$ & $0.433^{\star \star}$ & & $0.480^{\star \star}$ \\
\hline work enjoyment (WE) & $-0.064^{*}$ & $-0.127^{\star \star}$ & $-0.063^{*}$ & $0.326^{\star \star}$ & $0.480^{\star *}$ & \\
\hline \multicolumn{7}{|l|}{ job demands (JD) } \\
\hline task demands (TD) & $0.314^{\star \star}$ & $0.160^{\star \star}$ & $0.314^{\star *}$ & $0.311^{\star *}$ & $0.245^{* *}$ & -0.019 \\
\hline skills demands (SD) & 0.056 & $-0.084^{\star \star}$ & 0.055 & $0.224^{\star \star}$ & $0.340^{\star *}$ & $0.450^{\star *}$ \\
\hline supervising work (SW) & $0.225^{\star \star}$ & $0.097^{\star \star}$ & $0.224^{\star \star}$ & $0.175^{\star \star}$ & $0.141^{* *}$ & -0.046 \\
\hline psychological requirement (PR) & $0.375^{\star \star}$ & $0.192^{\star \star}$ & $0.374^{\star *}$ & $0.271^{\star *}$ & $0.126^{\star *}$ & -0.031 \\
\hline \multicolumn{7}{|l|}{ job resources (JR) } \\
\hline leadership support (LS) & $-0.083^{\star \star}$ & $-0.184^{\star \star}$ & $-0.083^{\star \star}$ & $0.122^{\star \star}$ & $0.279^{\star *}$ & $0.489^{\star \star}$ \\
\hline colleague support (CS) & $-0.099^{\star \star}$ & $-0.203^{\star *}$ & $-0.099^{\star *}$ & -0.005 & $0.227^{\star \star}$ & $0.359^{* *}$ \\
\hline facilities condition (FC) & $-0.150^{\star \star}$ & $-0.238^{\star \star}$ & $-0.150^{\star *}$ & $0.076^{*}$ & $0.233^{\star \star}$ & $0.484^{\star \star}$ \\
\hline work control (WC) & -0.050 & $-0.167^{\star \star}$ & -0.050 & $0.108^{\star \star}$ & $0.261^{\star *}$ & $0.495^{\star \star}$ \\
\hline organizational justice (OJ) & $-0.066^{*}$ & $-0.206^{\star *}$ & $-0.066^{*}$ & $0.154^{* \star}$ & $0.254^{\star \star}$ & $0.486^{\star *}$ \\
\hline
\end{tabular}

SF: sense fatigue; WL: work load; Wl: work involvement; D: drive; WE: work enjoyment.

${ }^{\star} p<0.05,{ }^{\star \star} p<0.01$

Potential predictors of the overwork are shown in Table 3. There was little difference in predictive factors for SF, WL, and overwork. Regarding the observed variables, task demands, psychological requirement, and colleague support were found to be significant predictors for SF, WL, and overall overwork (). While supervising work and facilities condition only affected WL and overwork (). Moreover, task demands, supervising work, and psychological requirements have significant positive effects on SF, WL, and 
overwork (); however, colleague support and facilities condition have significant negative effects on them (). Task demands and psychological requirements were the primary positive protective predictors for SF, WL, and overwork, while colleague support was the primary negatively protective predictors for them.

Table 3. Predictors of the overwork in enterprise staffs $(n=1047)$

Variable

\begin{tabular}{lllllll} 
Mean & \multicolumn{3}{l}{ Overwork } & & & \\
(SD) & Total & & $\mathrm{SF}$ & & $\mathrm{WL}$ & \\
\cline { 2 - 6 } & Estimate & $\mathrm{t}$ & Estimate & $\mathrm{t}$ & Estimate & $\mathrm{t}$ \\
& $($ Beta) & & $($ Beta) & & (Beta) &
\end{tabular}

job demands (JD)

\begin{tabular}{llllllll} 
task demands (TD) & 3.46 & 0.913 & $5.696^{* *}$ & 0.110 & $3.11^{* *}$ & 0.405 & $5.419^{* \star}$ \\
& $(0.47)$ & $(0.192)$ & & $(0.112)$ & & $(0.185)$ & \\
\hline skills demands (SD) & 3.58 & -0.027 & -0.252 & -0.003 & -0.128 & -0.013 & -0.250 \\
& $(0.78)$ & $(-0.010)$ & & $(-0.005)$ & & $(-0.010)$ & \\
\hline supervising work (SW) & 3.39 & 0.267 & $2.237^{\star *}$ & 0.025 & 0.934 & 0.119 & $2.136^{*}$ \\
& $(0.59)$ & $(0.071)$ & & $(0.031)$ & & $(0.068)$ & \\
$\begin{array}{l}\text { psychological } \\
\text { requirement (PR) }\end{array}$ & 3.21 & 0.916 & $8.453^{* *}$ & 0.090 & $3.765^{\star \star}$ & 0.412 & $8.165^{* \star}$ \\
& $(0.65)$ & $(0.270)$ & & $(0.128)$ & & $(0.264)$ &
\end{tabular}

\section{job resources (JR)}

leadership support

(LS)

3.41

$-0.118$

$-1.054-0.006$

$-0.263$

$-0.055$

$-1.049$

(0.84) (-0.045) (0.012)

$(-0.045)$

colleague support

(CS)

$3.76-0.305$

$-2.584^{\star *}-0.077$

$-2.967^{\star \star}$

$-0.115$

$-2.086^{*}$

(0.70) (-0.096)

$(-0.117)$

$(-0.112)$

facilities condition

(FC)

$3.41 \quad-0.342$

$-2.737^{\star \star}-0.052$

$-1.872$

$-0.146$

$-2.506^{*}$

(0.79) (-0.121) (-0.088)

$(-0.112)$

work control (WC)

$3.31 \quad 0.008$

0.084

$-0.027$

$-1.321$

0.018

0.408

(0.84) (0.003)

$(-0.049)$

(0.014)

organizational justice

3.21

0.131

1.268

$-0.030$

$-1.334$

0.081

1.679

(0.89) (0.053)

$(-0.059)$

(0.071)

SF: sense fatigue; WL: work load. 
Total: $\mathrm{R}^{2}=0.216$, adjust $\mathrm{R}^{2}=0.209$, Durbin Watson $(\mathrm{DW})=2.076, \mathrm{~F}=31.705$, Sig. $=0.000$.

SF: $R^{2}=0.113$, adjust $R^{2}=0.105$, Durbin Watson $(D W)=2.015, F=14.687$, Sig. $=0.000$.

WL: $R^{2}=0.195$, adjust $R^{2}=0.188$, Durbin Watson $(D W)=2.067, F=27.835$, Sig. $=0.000$.

Potential predictors of the three dimensions of workaholism are shown in Table 4. There were differences in predictive factors for WI, D and WE. As the observed variables task demands, skill demands, psychological requirement and organizational justice were found to be positively significant predictors for WI (), while colleague support opposite effect on WI (). Task demands, skills demands, work control and organizational justice also have a significant positive effect on D (). However, there were very different from WE, especially in the sub-scales of job demands. On the one hand, task demands and supervising work were negatively related to WE (), on the other hand, leadership support, work control and organizational justice were positively related to it (). Also task demands were the primary positively protective predictors for WI and D (), while as primary negatively protective predictors for WE ().

Table 4. Predictors of the three dimensions of workaholism in enterprise staffs ( $n=1047)$ 


\begin{tabular}{|c|c|c|c|c|c|c|}
\hline & WI & & D & & WE & \\
\hline & $\begin{array}{l}\text { Estimate } \\
\text { (Beta) }\end{array}$ & $\mathrm{t}$ & $\begin{array}{l}\text { Estimate } \\
\text { (Beta) }\end{array}$ & $\mathrm{t}$ & $\begin{array}{l}\text { Estimate } \\
\text { (Beta) }\end{array}$ & $\mathrm{t}$ \\
\hline \multicolumn{7}{|l|}{ job demands (JD) } \\
\hline task demands (TD) & $\begin{array}{l}0.338 \\
(0.236)\end{array}$ & $6.795^{\star \star}$ & $\begin{array}{l}0.243 \\
(0.176)\end{array}$ & $5.040^{\star \star}$ & $\begin{array}{l}-0.095 \\
(-0.060)\end{array}$ & $-2.009^{*}$ \\
\hline skills demands (SD) & $\begin{array}{l}0.067 \\
(0.078)\end{array}$ & $1.996^{*}$ & $\begin{array}{l}0.118 \\
(0.143)\end{array}$ & $3.632^{* \star}$ & $\begin{array}{l}0.186 \\
(0.197)\end{array}$ & $5.861^{\star \star}$ \\
\hline supervising work (SW) & $\begin{array}{l}0.018 \\
(0.016)\end{array}$ & 0.483 & $\begin{array}{l}0.013 \\
(0.367)\end{array}$ & 0.367 & $\begin{array}{l}-0.115 \\
(-0.091)\end{array}$ & $-3.273^{* \star}$ \\
\hline psychological requirement (PR) & $\begin{array}{l}0.142 \\
(0.139)\end{array}$ & $4.216^{\star *}$ & $\begin{array}{l}0.008 \\
(0.008)\end{array}$ & 0.235 & $\begin{array}{l}-0.029 \\
(-0.026)\end{array}$ & -0.913 \\
\hline
\end{tabular}

job resources (JR)

\begin{tabular}{lllllll}
\hline leadership support (LS) & 0.047 & 1.352 & 0.055 & 1.640 & 0.140 & $4.254^{* \star}$ \\
& $(0.059)$ & & $(0.072)$ & & $(0.159)$ & \\
\hline colleague support (CS) & -0.186 & $-5.077^{\star \star}$ & 0.007 & 0.201 & -0.002 & -0.071 \\
& $(-0.193)$ & & $(0.008)$ & & $(-0.002)$ & \\
\hline facilities condition (FC) & -0.012 & -0.306 & 0.006 & 0.147 & 0.063 & 1.700 \\
& $(-0.014)$ & & $(0.007)$ & & $(0.067)$ & \\
\hline work control (WC) & 0.029 & 1.009 & 0.076 & $2.722^{* *}$ & 0.192 & $7.008^{* \star}$ \\
& $(0.036)$ & & $(0.098)$ & & $(0.217)$ & \\
\hline organizational justice (OJ) & 0.121 & $3.763^{* \star}$ & 0.063 & $2.030^{*}$ & 0.130 & $4.278^{* \star}$ \\
& $(0.161)$ & & $(0.087)$ & & $(0.157)$ &
\end{tabular}

WI: work involvement; D: drive; WE: work enjoyment.

WI: $R^{2}=0.167$, adjust $R^{2}=0.160$, Durbin Watson $(D W)=1.914, F=23.149$, Sig. $=0.000$.

$D: R^{2}=0.165$, adjust $R^{2}=0.158$, Durbin Watson $(D W)=1.847, F=22.796$, Sig. $=0.000$. 
WE: $R^{2}=0.388$, adjust $R^{2}=0.383$, Durbin Watson $(D W)=1.895, F=72.995$, Sig. $=0.000$.

The SEM presented in Figure 1 indicated workaholism and job demands have direct positive effects on overwork, whereas job resources have a negative effect on overwork among Chinese enterprise staffs in this study. Moreover, job resources and job demands have also indirect effects on overwork. Table4 shows the estimates of direct, indirect and total effects of workaholism and overwork. Of all the total effects, job demands is the greatest (0.366), followed by job resources (-0.314), and workaholism (0.151). Moreover, job resources have significant inhibitory effects on overwork, while job demands has a promoting effect. According to the mediation effect of inspection, workaholism plays a significant intermediary role in this path. Scholars point out, regarding the calculation method of the intermediary effect, that, on the one hand, in the path of Job resources $\rightarrow$ overwork the mediation effect accounted for $15.0 \%$ of the total effect; on the other hand, in the path of Job demands $\rightarrow$ overwork it accounted for $12.6 \%$ [59-60]. Workaholism also has a significant effect on overwork, but the effect value is significantly lower than those for job demands and job resources.

Table 5. Direct effect, indirect effect and total effects on overwork

\begin{tabular}{llllll} 
path & $\begin{array}{l}\text { Standard } \\
\text { error }\end{array}$ & t-value & $\begin{array}{c}\text { Direct } \\
\text { effect }\end{array}$ & $\begin{array}{c}\text { Indirect } \\
\text { effect }\end{array}$ & $\begin{array}{c}\text { Total } \\
\text { effect }\end{array}$ \\
\hline $\begin{array}{l}\text { Job resources } \\
\rightarrow \text { Workaholism }\end{array}$ & 0.024 & $10.587^{\star \star \star}$ & 0.311 & -- & 0.311 \\
\hline $\begin{array}{l}\text { Job demands } \\
\rightarrow \text { Workaholism }\end{array}$ & 0.036 & $10.81^{\star \star \star}$ & 0.305 & -- & 0.305 \\
\hline Workaholism $\rightarrow$ Overwork & 0.132 & $4.290^{\star \star \star}$ & 0.151 & -- & 0.151 \\
\hline Job resources $\rightarrow$ Overwork & 0.110 & $1.058^{* \star \star}$ & -0.361 & 0.047 & -0.314 \\
\hline Job demands $\rightarrow$ Overwork & 0.165 & $-9.774^{\star \star \star}$ & 0.320 & 0.046 & 0.366
\end{tabular}

***

Figure 1. TSEM for overwork among enterprise staffs

SF: sense fatigue; WL: work load; WA: workaholism; WI: work involvement; D: drive; WE: work enjoyment; JR: job resources; LS: leader supply; CS: college supply; FC: facilities condition; WC: work control; OJ: organizational justice; JD: job demands; TD: task demands; SD: skill demands; SW: supervising work; PR: psychological requirement.

\section{Discussion}

Overwork has gradually become the common for work life for Chinese enterprise employees. China has seen rapid economic development over the years; at the same time, the phenomenon of long-time work 
and overwork also gradually emerged. The degree of overwork is observed through warning signals issued by the body indicating when physical and mental health are in a state of imbalance, which can eventually will lead to 'karoshi'. Although some scholars have conducted empirical analysis, more research has focused on general descriptive analysis, and very few studies have constructed and proved the reliability of a usable model. It is important to know the influence of the factors of overwork, for such knowledge is beneficial to standardizing enterprise management.

In this study has utilized a more comprehensive model to evaluate the relationships among workaholism, job demands, job resources, and overwork. The key findings of the present study confirm the relationship between them. Job demands and job resources both directly and indirectly affected overwork. Moreover, job resources have significant inhibitory effects on overwork, while job demands have a promoting effect on it. Workaholism plays a significant intermediary role between them in this path.

A negative correlation was observed between job resources and overwork, based on the correlation analysis and result from SEM. It means, the better job resources, the more likely can reduce and restrain enterprise staffs overwork, especially in the aspect of colleagues' support and facilities' condition. In fact, organizational climate and employee relations in the enterprise are called 'soft environment' which is an invisible aspect of work-life. Harmonious relations in organizations allow for people to work together for common progress. Help and support from colleagues reflect the harmonious relationship among them. Facilities condition be provided also can inhibit and ease overwork to a certain extent. Companies to provide more rich resource, the staffs' work is more smoothly, work efficiency will be improved, and it will reduce a lot of worries for staffs.

A positive correlation was observed between job demands and overwork. The greater the job demands, the larger and deeper the degree of overwork. Task demands, supervising work, and psychological requirements have significant effects on overwork. With increasingly fierce market competition, and companies being in constant pursuit of profit and production efficiency, tasks are often onerous but understaffing and overtime has become the norm for work life. Additionally, strict management can increase workloads for employees. Demands of complex physical and mental tasks lead to fatigue. The physical and mental health of workers relies on a reasonable frequency of temporary ease. Companies should strictly enforce the rules of overtime and ensure staffs' right of rest is being met.

Workaholism includes three dimensions: work investment, drive, and work enjoyment. Work investment and drive were positively related to sense fatigue and workload (), while work enjoyment was negative related to them (), based on the multiple linear regression. The results regarding companies employees who actively threw themselves into work compared to those who are forced to work hard demonstrate an important difference. Full of enthusiasm for work, those who readily engage in the work can feel this positive energy and this effectively promotes productivity. However, in Chinese companies, there are some workers who indicate that they are in a state of knowing they are able to complete tasks but they feel no longer feel joy at work, which is the state of being a 'workaholic'. As seen in Table 4, leader support and work control can add to feelings of enjoyment at work, and, at the same time, task demands and 
supervising work can reduce it. Therefore, the leaders who care about their subordinates and sometimes assist them in handling difficult problems at work actually help workers gain more of a sense of making subordinates feel happier and helping them find the fun in their work. These results indicate that subordinates need to be encouraged and motivated.

\section{Limitations and Future Research Directions}

The strengths of this study include the large sample size and the use of a more comprehensive model to possibility explore the correlation among workaholism, job demands, job resources and overwork. Used internationally widespread measurement, such as the Workers Fatigue Accumulated Degree by WFAD-SQ, WorkBAT, and JCQ. It is possible to apply our findings in an international context. This study contributes to the effectiveness of organizational interventions employed to avoid overwork among enterprise staffs. The data collection and access were approved and supported by China Moderate Labour Research Centre, to ensure the effective data sources. The survey covered most provinces and all of the primary industries in China.

However, a number of limitations should be considered in interpreting the results. First, all measures were based on self-reports which likely existed bias, but no sensitive and extreme issues were included in this questionnaire. And we have carried on the preliminary investigation before the formal visiting. Second, this study is a cross-sectional design, if we can track the sample or use longitudinal approach would be valuable and significant in the area of overwork. But there is no research like it, moreover, using crosssectional data to explore the complex relationship among workaholism, job demands, job resources and overwork is also rare in other similar all other studies.

\section{Conclusions}

The effect factors of overwork among enterprise staffs by workaholism, job demands and wore environment were provided in this study. Job resources have significant inhibitory effects on overwork, while job demands have overwork-promoting effects. Workaholism plays a significant intermediary role between job demands, job resources, and overwork. Thus, the results can be used to prevent enterprise employees from becoming overworked and may lead to considerable progress in improving research about overwork in China. This study suggests that companies and organizations should strictly enforce the rules of overtime, ensure staffs' right of rest, and establish a harmonious working relationship between employees is very important.

\section{Abbreviations}

Job content qualifications, JCQ

Structural equation modelling, SEM

Job Demands-Resources, JD-R

Page 15/21 
Workaholism Battery, WorkBAT

Workers Fatigue Accumulated Degree by Self-Diagnostic Questionnaire, WFAD-SQ

job demands-resource model, JD-R Model

China Labor-force Dynamics Survey, CLDS

\section{Declarations}

Ethics approval and consent to participate: All procedures performed in studies involving human participants were performed in accordance with the ethical standards of the institutional and/or national research committee and the 1964 Helsinki Declaration and its later amendments or comparable ethical standards. The informed consent obtained from study participants was written. This research was approved by the Human Research Ethics Committee at School of Labour Economics, Capital University of Economics, and Business, and China Moderate Labour Research Centre.

Consent to publish: Not applicable.

Availability of data and materials: All source data analyzed during this study are available via the following website: https://www.wjx.cn/report/4505575.aspx. The datasets used and analyzed during the current study are available from the corresponding author on reasonable request.

Competing Interests: The authors declare no conflict of interest.

Funding: This work has been funded by the project supported by Beijing postdoctoral fund 'Research on the formation mechanism of overwork and the realization path of health management in China' (23400057210008). The 66th batch of general grants from China Postdoctoral Science Foundation 'Research on the problem of overwork of Internet employees under the' healthy China 'strategy' (2019M660711). Study and expound the special project of the National Social Science Foundation of the 19th National Congress of the Communist Party of China on 'double helix driving mechanism, path and Countermeasures for the cultivation of entrepreneurship in the new era' (18VSJ084).

Author Contributions: All authors contributed to the conceptualization of the study. W. X. designed and carried out this study. She also conducted the data analyses. All authors contributed to interpreting the findings, and collaborated on the different drafts of the manuscript. All authors approved the final manuscript's submission for publication.

Acknowledgments: We thank the School of Labour Economics, Capital University of Economics, and Business, and China Moderate Labour Research Centre or access to the data used in this study. These organizations had no input to data analysis or interpretation.

\section{Author details:}


${ }^{1}$ Capital University of Economics and Business, School of Business Administration, Beijing, 100070, China.

${ }^{2}$ Beijing International Studies University, School of Tourism Science, Beijing, 100024, China.

${ }^{3}$ School of Law and Letters, Ehime University, Ehime, 7908577, Japan.

\section{References}

1. Marx, K.H. Economic and philosophical manuscripts 1844 (2008); People's Publishing House: Beijing, China. (In Chinese)

2. Nishiyama, K.; Johnson, JV. (1997). Karoshi-death from overwork: occupational health consequences of Japanese production management, International Journal of Health Services, 27, 625-641.

3. Haruo, S. (1989). Labour economics; School of economics press: Beijing, China. (In Chinese)

4. Uehata, T.; Sasagawa, N. (1979). Studies of karoshi: on working conditions before onset, Industrial Medicine, 06,640-641. (In Japanese)

5. Yang, H.Q.; Han, F.X.; Xiao, H.E. (2009). Investigation on overwork of employees in Beijing, Population \& Economics, $02,33-41$. (In Chinese)

6. Uehata, T. (1993). Study of death from overwork, Brand Center: Japan. (in Japanese)

7. Fukuchi, F. (2008). Fatigue, overwork and health of workers, Kamogawa Press: Japan, 2008. (in Japanese)

8. Senda, T. (2003). Overwork in Japan: to prevent overwork, Economics, 02,101-103. (In Japanese)

9. Wang, D. (2011). A study for overwork of chinese knowledge workers, Capital University of Economics and Business Press: Beijing, China. (In Chinese)

10. Meng, X.D. (2014). The research for cause of overwork: general principles and experience in China, China Labourand Social Security Press: Beijing, China. (In Chinese)

11. Wang, X.; Yang, H.Q. (2016). A study on 'overwork' of 'forced spontaneous' employees in Companies, Soft Science, 10, 104-108. (In Chinese)

12. Kumazawa, M. (2010). Karoshi, Iwanami Book Store: Tokyo, Japan. (In Japanese)

13. Zhuang, J.Z. (2018). From the managed hand to the managed heart: study on overtime work from the perspective of labourprocess, Sociological Studie, 03, 74-91. (In Chinese)

14. Zhang, Z.Y.; Jiang, L. (2019). Study on the influence of overtime attitude on the degree of overwork, Productivity Research, 07,112-115. (In Chinese)

15. Mazzetti G.; Schaufeli, W.B.; Guglielmi, G. (2014). Are workaholics born or made? Relations of workaholism with person characteristics and overwork climate, International Journal of Stress 
Management, 21,227-254.

16. Ogura, K. (2011). Overworked society Nippon: approach to the situation of long working powers, Japanese Economy Business Human Library: Japan. (In Japanese)

17. Shi, J.Z. (2016). A study on the problem of overwork in contemporary China, China Economic Publishing House: China. (In Chinese)

18. Guo, F.M.; Zhang, S.W. (2018). The impact of the minimum wage increase on the overwork of lowincome migrant workers, Chinese Journal of Population Science, 01, 42-56. (In Chinese)

19. Shang, K.; Xing, N. (2019). Game Analysis on the formation mechanism of overwork, Journal of China University of LabourRelations, 08, 39-44. (In Chinese)

20. Morioka, K. (2005). An era of overwork, Iwanami Book Store: Tokyo, Japan. (In Japanese)

21. Kuroda, S.; Yamamoto, I. (2014). Employee mental health and working hours: verification using employee panel data, Economic and Industrial Research Institute, RIETI Policy discussion paper NO.20. (In Japanese)

22. Jacobs, J.A. (2004). Overworked faculty: Job stresses and family demands, Annals of The American Academy of Political and Social Science, 596, 104-129.

23. Youngjoo, Cha.; Kim,W. (2014). Overwork and the slow convergence in the gender gap in wages, American Sociological Review, 03, 457-484.

24. Meijman, T.F.; Mulder, G. (1998). Psychological aspects of workload ; Handbook of Work and Organizational Psychology, Erlbaum, Hove.

25. Bakker, A.B.; Demerouti, E.; De Boer, E.; Schaufeli, W.B. (2003). Job demands and job resources as predictors of absence duration and frequency, Journal of Vocational Behaviour, 62, 341-356.

26. Akiomi, I.; Norito, K; Kanami, T.; Akihito, S.; Kimiko, T.; Mayuko, N. (2013). Job demands, job resources, and work engagement of Japanese employees: a prospective cohort study, International Archives of Occupational and Environmental Health, 04, 441-449.

27. Ke DS. (2012). Overwork, Stroke, and Karoshi-death from Overwork, Acta neurologica Taiwanica, 2012, 02, 54-59.

28. Cecilie, S.A.; Ståle, P.; Torbjørn, T. (2018). Workaholism as a mediator between work-related stressors and health outcomes, International Journal of Environmental Research and Public Health, 15, 73-85 .

29. Karasek, R.; Theorell, T. (1990). Health, Work, Stress, Productivity, and the Reconstruction of Working Life; Basic Books: New York, NY, USA.

30. Snir, R.; Harpaz, I. (2012). Beyond workaholism: Towards a general model of heavy work investment. Manag. 22, 232-243.

31. Loscalzo, Y.; Giannini, M. (2017). Clinical conceptualization of workaholism: A comprehensive model. Psychol. Rev. 2017, 7, 306-329.

32. Van Beek, I.; Taris, T.W.; Schaufeli, W.B. (2011). Workaholic and work engaged employees: Dead ringers or worlds apart? Occup. Health Psychol, 16, 468-482. 
33. Van den Broeck, A.; Vander Elst, T.; Baillien, E.; Sercu, M.; Schouteden, M.; Dewitte, H.; Godderis Lode. (2017). Job demands, job resources, burnout, work engagement, and their relationships. Occup. Environ. Med., 59, 369-376.

34. Yin, H.; Huang, S.; Wang, W. (2016). Work environment characteristics and teacher well-being: The mediation of emotion regulation strategies. J. Environ. Res. Public Health, 13, 907.

35. Bakker, A.B.; Albrecht, S.L.; Leiter, M.P. (2011), Key questions regarding work engagement. J. Work Organ. Psychol, 20, 4-28.

36. Kristina, L.; Örjan, E.; Lena V. K.; Maria, E.; Victoria, B. (2019). Job demand-control-support model as related to objectively measured physical activity and sedentary time in working women and men, $\mathrm{J}$. Environ. Res. Public Health, 16, 3370-3380.

37. Industrial Health Division, Ministry of Health, Labourand Welfare Bureau of Labour Standards. (2003). About publish workers' fatigue diagnostic checklist', The LabourStandards, 8, 2-4. (In Japanese)

38. Spence, J.T.; Robbins, A.S. (1992). Workaholism- definition, measurement, and preliminary results', Journal of Personality Assessment, 58, 160-178.

39. Bakker,A.B.; Demerouti, E.; Verbeke, W. (2004). Using the job demands-resources model to predict burnout and performance', Human Resource Management, 43, 83-104.

40. Bakker,A.B.; Demerouti, E. (2007). The job demands- resources model: state of the art', Journal of Managerial Psychology, 22, 309-328.

41. Cui, X.; Lu, X.; Hisada, A.; Fujiwara, Y.; Katoh, T. (2015). The correlation between mental health and multiple chemical sensitivity: A survey study in Japanese workers. Health Prev. Med, 20, 123-129.

42. Tsuchiya, M.; Mori, E.; Sakajo, A.; Iwata, H.; Maehara, K.; Tamakoshi, K. (2016). Cross-sectional and longitudinal validation of a 13-item fatigue scale among Japanese postpartum mothers. J. Nurs. Pract. 22, 5-13.

43. Tang, C.; Liu, C.; Fang, P.; Xiang, Y.; Min, R. (2019). Work-related accumulated fatigue among doctors in tertiary hospitals: a cross-sectional survey in six provinces of China. International Journal of Environmental Research and Public Health, 16, 3049-3062.

44. Meng, X.D.; Wang, X. (2014). Research for condition and influence factors of overwork among enterprise employees, based on the analysis of 'push-pull' model, Population \& Economics, 03, 92100. (In Chinese)

45. Huang, H.; Geng, D.; Chou, J.Y. (2009). Fatigue accumulation degrees of self-test and overwork prevention, Human Resource Development in China, 9, 35-37. (In Chinese)

46. Wang,D.; Yang, H.Q. (2010). The situation of companies and institutions workers' overwork in Beijing, Human Resource Development in China, 38-39. (In Chinese)

47. Wang,D. (2010). The Theory and empirical of overwork among knowledge workers in China; Ph.D. Thesis: Capital University of Economics and Business. (In Chinese) 
48. Andreassen, C.S.; Hetland, J.; Pallesen, S. (2014). Psychometric aassessment of workaholism measures, Journal of Managerial Psychology, 29, 7-24.

49. Shimazu, A.; Schaufeli, WB. (2009). Is workaholism good or bad for employee well-being? the distinctiveness of workaholism and work engagement among Japanese employees, Industrial Health, 47, 495-502.

50. Shimazu, A.; Schaufeli, WB.; Kubota, K.; Kawakam, N. (2012). Do workaholism and work engagement predict employee well-being and performance in opposite directions?, Industrial Health, 50, 316-321.

51. Shimazu, A.; Schaufeli, WB.; Kubota, K.; Kawakam, N. (2015). Workaholism vs. work engagement: the two different predictors of future well-being and performance', International Journal of Behavioural Medicine, 22, 18-23.

52. Kanai, A.; Wakabayashi, M.; Fling, S. (1996). Workaholism among employees in Japanese corporations: an examination based on the Japanese version of the workaholism scales, Japanese Psychological Research, 38, 192-203.

53. Karasek, R. A. (1979). Job Demands, Job decision latitude, and mental strain: implications for job design, Administrative Science Quarterly, 24, 285-308.

54. Karasek RA. (1998). The Job Content Questionnaire (JCQ): an instrument for internationally comparative assessments of psychosocial job characteristics, Journal of Occupational Health Psychology, 3, 322-355.

55. Sha, M; Liu, P.; Jian, L.; Na, D. (2003). The validation of Chinese version of job content questionnaire in health professionals', China Occupational Medicine, 3, 24-27. (In Chinese)

56. Zhang, C.Y.; Zhang, J.P.; Zhang, P.P.; Zhang, J.Q. (2010). The formation mechanism and management methods of overwork among employees, based on the job requirements, resource model, Human Resource Development in China, 9, 30-34. (In Chinese)

57. Jiang, H.Y.;Sun, P.Z.; Liu, H.E. (2012). Empirical study of influencing of job resources to R\&D staffs work engagement: the mediating role of psychological capital, Science \& Technology Progress and Policy, 6, 137-141. (In Chinese)

58. Yang, Y.; Deng, C.P. (2010). A study on the reliability and validity of NASA-TLX as a measurement of subjective fatigue after computer operation, Psychological Research, 3, 36-41. (In Chinese)

59. Wen, Z.L.; Chang, L.; Hao, K.T.; Liu, H.Y. (2004). Testing and application of the mediating effects, Acta Psychologica Sinica, 36, 614-620. (In Chinese)

60. Wen, Z.L.; Hao, K.T.; Chang, L. A. (2005). comparison of moderator and mediator their applications, Acta Psychologica Sinica, 37, 268-274. (In Chinese)

\section{Figures}




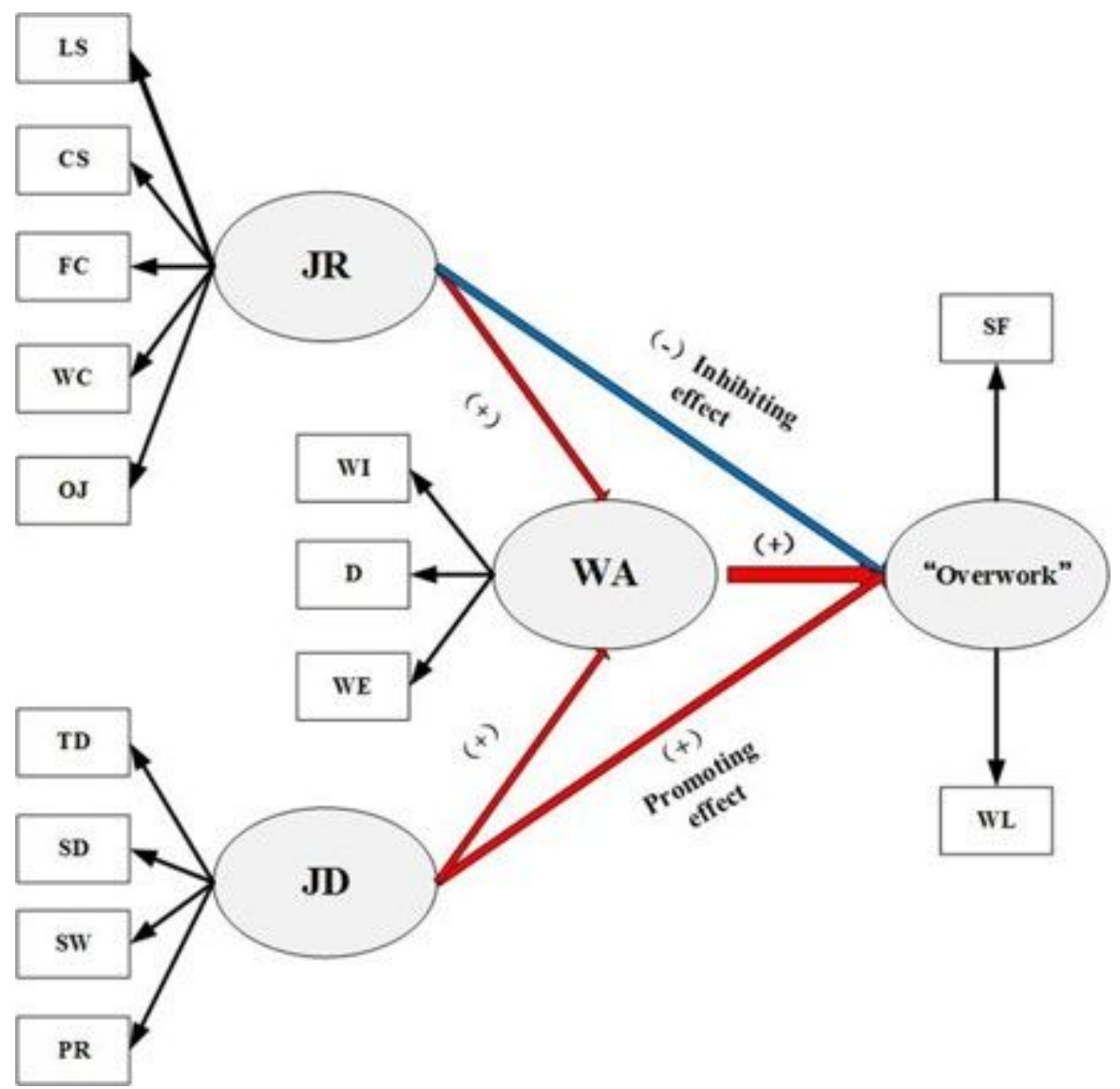

Figure 1

TSEM for overwork among enterprise staffs SF: sense fatigue; WL: work load; WA: workaholism; WI: work involvement; D: drive; WE: work enjoyment; JR: job resources; LS: leader supply; CS: college supply; FC: facilities condition; WC: work control; OJ: organizational justice; JD: job demands; TD: task demands; SD: skill demands; SW: supervising work; PR: psychological requirement. 